\title{
Effects of white-tailed deer habitat use preferences on southern cattle fever tick eradication: simulating impact on "pasture vacation" strategies
}

\author{
M. Sofia Agudelo ${ }^{1,2^{*}}$ (], William E. Grant ${ }^{3}$ and Hsiao-Hsuan Wang ${ }^{3}$ (I)
}

\begin{abstract}
Background: Rhipicephalus (Boophilus) annulatus and Rhipicephalus (Boophilus) microplus (southern cattle fever tick; SCFT), collectively known as cattle-fever ticks (CFTs), are vectors of protozoal parasites (Babesia bigemina and Babesia bovis) that cause bovine babesiosis (also known as cattle fever). One traditional strategy for CFT eradication involves the implementation of a "pasture vacation," which involves removing cattle (Bos taurus) from an infested pasture for an extended period of time. However, vacated pastures are often inhabited by wildlife hosts, such as white-tailed deer (WTD; Odocoileus virginianus), which can serve as alternate hosts for questing CFTs. We hypothesized that the distribution of host-seeking larvae among habitat types post-pasture vacation would reflect habitat use patterns of WTD, and in turn, affect the subsequent rate of pasture infestation by CFT.

Methods: We adapted a spatially explicit, individual-based model to simulate interactions among SCFT, cattle, and WTD as a tool to investigate the potential effects of WTD habitat use preferences on the efficacy of a pasture vacation. We parameterized the model to represent conditions typical of rangelands in south Texas, USA, simulated a 1-year pasture vacation under different assumptions regarding WTD habitat use preferences, and summarized effects on efficacy through (1) time post-vacation to reach $100 \%$ of pre-vacation densities of host-seeking larvae, and (2) the ecological conditions that resulted in the lowest host-seeking larval densities following pasture vacation.
\end{abstract}

Results: Larval densities at the landscape scale varied seasonally in a similar manner over the entire simulation period, regardless of WTD habitat use preferences. Following the removal of cattle, larval densities declined sharply to $<100$ larvae/ha. Following the return of cattle, larval densities increased to $>60 \%$ of pre-vacation densities $\approx 21$ weeks post-vacation, and reached pre-vacation levels in less than a year. Trends in larval densities in different habitat types paralleled those at the landscape scale over the entire simulation period, but differed quantitatively from one another during the pasture vacation. Relative larval densities (highest to lowest) shifted from (1) wood/ shrub, (2) grass, (3) mixed-brush during the pre-vacation period to (1) mixed-brush, (2) wood/shrub, (3) grass or (1) wood/shrub, (2) mixed-brush, (3) grass during the post-vacation period, depending on WTD habitat use preferences.

Conclusions: By monitoring WTD-driven shifts in distributions of SCFT host-seeking larvae among habitat types during simulated pasture vacation experiments, we were able to identify potential SCFT refugia from which

${ }^{*}$ Correspondence: sagudelo@west-inc.com

2 Present Address: Western EcoSystems Technology, Inc. (WEST), Bismarck, ND 58503, USA

Full list of author information is available at the end of the article

c) The Author(s) 2021. This article is licensed under a Creative Commons Attribution 4.0 International License, which permits use, sharing, adaptation, distribution and reproduction in any medium or format, as long as you give appropriate credit to the original author(s) and the source, provide a link to the Creative Commons licence, and indicate if changes were made. The images or other third party material in this article are included in the article's Creative Commons licence, unless indicated otherwise in a credit line to the material. If material is not included in the article's Creative Commons licence and your intended use is not permitted by statutory regulation or exceeds the permitted use, you will need to obtain permission directly from the copyright holder. To view a copy of this licence, visit http://creativeco mmons.org/licenses/by/4.0/. The Creative Commons Public Domain Dedication waiver (http://creativecommons.org/publicdomain/ zero/1.0/) applies to the data made available in this article, unless otherwise stated in a credit line to the data. 
recrudescence of infestations could originate. Such information could inform timely applications of acaricides to specific refugia habitats immediately prior to the termination of pasture vacations.

Keywords: Cattle Fever Tick Eradication Program, Host-parasite interaction, Individual-based model, Integrated tick management research, Rhipicephalus sp., Spatially explicit model

\section{Background}

Rhipicephalus (Boophilus) annulatus and Rhipicephalus (Boophilus) microplus (southern cattle fever tick; SCFT), collectively known as cattle-fever ticks (CFTs), are vectors of protozoal parasites (Babesia bigemina and Babesia bovis) that cause bovine babesiosis (cattle fever), which is considered the most economically important livestock disease worldwide [1]. Thus, keeping cattle (Bos taurus) herds free of bovine babesiosis is an important economic and animal health priority [2, 3]. CFT and Babesia sp. are prevalent in Mexico, but since the 1940s have been confined in the USA primarily within the permanent CFT quarantine zone, which is along the border with Mexico and is maintained by the Cattle Fever Tick Eradication Program (CFTEP) [4]. However, in 2009, an area outside the permanent quarantine zone covering $>400,000$ hectares (ha) in south Texas, USA, was quarantined due to CFT infestations [5]; as of $2019, \approx 300,000$ ha outside the permanent quarantine zone is under CFT quarantine [6].

Historically, the success of the CFTEP has depended largely on the host specificity of CFTs [7]. CFTs are one-host ticks that complete their life cycle on a single host. Off-host (host-seeking) larvae attach to a host, feed and molt to nymphs (1 week), and then feed again and molt to adults (1 week) on the same host animal. Adult females mate and engorge on the host (1-2 weeks), then detach and fall to the ground where they lay large egg masses [8] and die, usually within a few days. Survival of off-host life stages (eggs, larvae) is affected by the climatic conditions to which they are exposed, which varies depending on the habitat type in which the eggs were laid. Further, the location of egg masses reflects the habitat use of hosts, and the likelihood of CFTs encountering host species depends on host community composition and density $[9,10]$.

Climate variables such as temperature, saturation deficit, and precipitation are known to affect the survival and development of CFT $[11,12]$. Although publicly available information on host-seeking larvae densities does not exist for south Texas, simulation modeling approaches under typical weather patterns of south Texas have shown that CFT populations oscillate in response to favorable conditions for host-seeking larval survival in spring and fall (characterized by increased precipitation and low saturation deficit), and unfavorable conditions in summer and winter (characterized by high and low temperatures compounded with varying conditions of precipitation and saturation deficit) [10]. Studies have suggested that the interaction between weather and habitat variables strongly influences the survival of host-seeking larvae in south Texas [13]. Information provided by Teel et al. [9, $14,15]$ indicates that canopy cover attributes of different habitat types interact with abiotic factors to characterize the landscape as good, fair, or poor habitats for CFT survival and development. For example, habitat suitability in south Texas rangelands varies from good in wood/ shrub-canopied habitats, to fair in mixed-brush habitats, to poor in uncanopied grass habitats.

Although cattle are the main CFT hosts, the white-tailed deer (WTD; Odocoileus virginianus) is also a confirmed host [16]. Serologic and molecular evidence suggests that WTD in northern Mexico and southern Texas carry bovine babesiosis [17], and genetic data suggest WTD likely serve as a source for tick populations that will eventually feed on cattle [18]. Both field and modeling studies have examined the potential role of ungulate hosts related to disease transmission [19], the effects of seasonal fluctuations in host communities on the dynamics of infectious disease [20], and the efficacy of targeting acaricides at specific types of hosts [21]. Wang et al. [10] focused specifically on modeling the impact of interactions between cattle and WTD on SCFT-eradication methods. These authors suggested that WTD could reduce the efficacy of eradication efforts by maintaining viable tick populations during eradication treatments aimed at cattle [10].

Two traditional methods for CFT eradication involve the use of acaricides and implementation of a "pasture vacation" [22], with the latter defined as the removal of cattle from a pasture for an extended length of time [23, 24]. The efficacy of acaricides is potentially compromised by several factors, including the evolution of resistance of CFTs to them [25], a limited ability to apply acaricides to wildlife hosts [26], and the existence of diverse plant communities that provide an abundance of habitats favorable for the survival of CFTs [3]. Acaricide methods employed by the CFTEP to treat cattle on infested premises require treatment of the entire herd at 2-week intervals to assure 100\% CFT elimination [27]. The practice of vacating pastures also remains a viable option in the CFTEP, although there have been an increasing number of failures of this method, which often have been related to the presence of WTD [16]. 
Epidemiological analysis of CFT infestations have indicated that WTD can compromise eradication efforts by sustaining and dispersing CFTs within and outside the permanent quarantine zone [16]. The degree to which WTD can sustain or re-infest an area with CFTs depends in large part on the distribution of different habitat types across the landscape. Habitat use preferences of WTD, although widely studied [28-31], are poorly understood within the context of CFT management strategies. Field studies report habitat use patterns with varying degrees of specificity, which are case specific and difficult to compare due to the inevitable confounding effect of habitat preference versus availability. Nonetheless, some general patterns emerge. Pollock et al. [32] reported that in south Texas the areas more heavily used year-round by WTD were characterized by shrub vegetation with high canopy cover and high woody species diversity. Avery et al. [33] found that WTD in west-central Texas spent $54 \%$ of their time in woody (shrub) areas. DeYoung et al. [34] reported that WTD in south Texas spent $65-76 \%$ of their time in woody (shrub) areas depending on their own nutritional status.

The importance of the explicit consideration of habitat use by alternative hosts such as WTD when planning efforts to eliminate CFT infestations has been become a topic of much interest [3]. Wang et al. [10] suggested that WTD could undermine the efficacy of CFT eradication efforts by dispersing engorged female ticks into, and collecting host-seeking larvae from, habitats favorable for the survival and development of off-host life stages, thus creating tick refugia during eradication treatments aimed at cattle. In south Texas rangelands, WTD use habitats characterized by shrub vegetation with high canopy cover and high woody species diversity [32, 34]. These canopied plant communities provide habitats favorable for the survival and development of off-host CFT life stages, and also provide good browse for WTD (all of the shrubs mentioned by these authors in these plant communities are palatable to WTD except for whitebrush Aloysia gratissima). Thus, exploration of the WTD-mediated distribution of host-seeking CFT larvae during and immediately following pasture vacation has the potential to suggest novel approaches to the elimination of CFT infestations.

In the present study, we adapted the model of Wang et al. [10] to investigate potential effects of WTD habitat preferences on the eradication of SCFT infestations. More specifically, we simulated the effects of changes in WTD habitat preferences for good SCFT habitat (wood/ shrub) on the distribution of host-seeking larvae during and after a 1-year pasture vacation, applied under climate and landscape conditions typical of rangelands in south Texas.

\section{Methods}

\section{Model description}

To investigate potential effects of WTD habitat use on SCFT-eradication efforts, we used the spatially explicit, individual-based model of Wang et al. [10]. The model is designed to simulate the effects of shifts in the spatialtemporal patterns of host (cattle and WTD) habitat use on the dynamics of SCFT populations (Fig. 1). A complete model description following the Overview, Design concepts, Details protocol $[35,36]$ is provided in Wang et al. [10]. Figure 2 lists the steps involved in the model's execution. Below, we provide a summary of the detailed Overview, Design concepts, Details model description, following the format suggested by Grimm et al. [37]. The format focuses on model (1) purpose, (2) patterns, (3) entities, (4) state variables, (5) spatial and temporal scales, (6) processes, and (7) design concept. We have italicized these terms in the description below.

The overall purpose of the model is to examine how the presence of WTD affects the efficacy of pasture vacation as a CFT eradication strategy in south Texas. Specifically, we hypothesized that the post-vacation distribution of host-seeking larvae among habitat types resulting from habitat use patterns of WTD affects subsequent patterns of pasture infestation. We consider the model realistic enough for this purpose based on its ability to generate ecologically interpretable spatial-temporal distribution patterns of host-seeking larvae under rangeland conditions typical of south Texas: (1) the mean density of host-seeking larvae exhibits oscillations consistent with their exposure to environmental conditions during the off-host phase of their life cycle (Fig. 4b in Wang et al. [10]); (2) annual variation in host-seeking larvae follows a bimodal pattern, with a spring increase and summer decline, followed by a fall increase and winter decline (Fig. 4e, f in Wang et al. [10]); (3) the highest density host-seeking larvae populations occur in wood/shrub habitats and along edges of mixed-brush, which results from heavier usage of grass and mixed-brush habitats by cattle, and heavier usage along edges of mixed-brush and wood/shrub by WTD (Fig. 5 in Wang et al. [10]).

Entities represented in the model include (1) 900, square, 1-ha habitat cells, and (2) several hundred individual mammalian hosts (cattle and WTD). State variables of habitat cells include location, habitat type (wood/ shrub, mixed-brush, or grass), and current numbers of SCFT eggs, larvae, and engorged (fed) adults in each weekly age-class located in the cell, as well as the current numbers of cattle and WTD located in the cell. State variables of individual hosts include the location of the center of activity range, current location, habitat type of current location, relative habitat preference [low (0) to high (1)] for each habitat type, size of activity range (ha), 


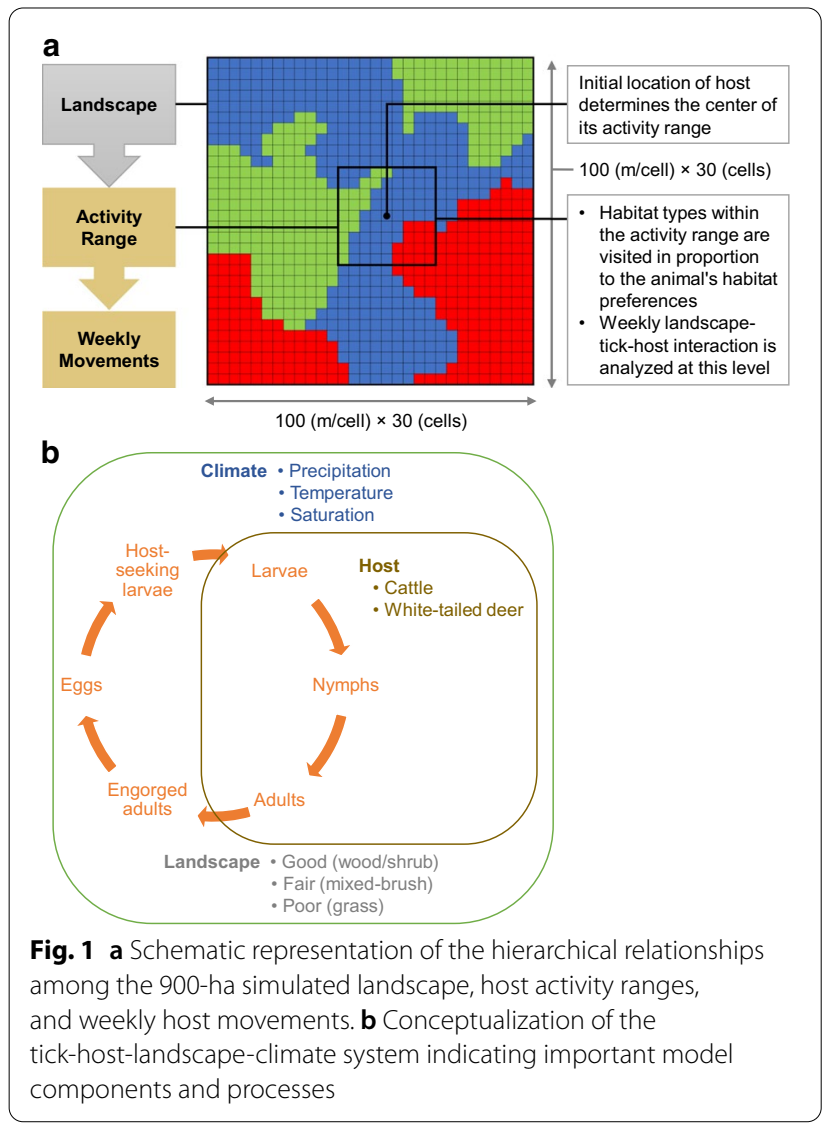

relative number of larvae they can carry at any given time (1.0 for cattle, 0.1 for WTD), and numbers of larval, nymphal, and adult SCFTs in each age-class that hosts currently carry. Spatial scales are defined in terms of the 900, square, 1-ha habitat cells. The temporal scales explored are a weekly time step for a total of 3 years for calculation of SCFT development and survival. However, hosts move about the landscape 30 times per week, acquiring and depositing SCFTs among the habitat cells they visit.

The most important processes represented in the model include (1) temperature-dependent and habitat-specific development and survival of off-host SCFTs, (2) host-specific survival of on-host SCFTs and host-specific fecundity of deposited (fed) SCFTs, (3) the movement of hosts based on habitat preferences, and (4) host-specific and habitatspecific acquisition and deposition of SCFTs. Tick development, survival, and reproduction occur at the beginning of each weekly time step. Host movement, tick acquisition, and tick deposition occur 30 times within each weekly time step. (Note that tick acquisition and deposition do not necessarily occur with each individual host movement).

The most important design concept is that the SCFT life cycle is influenced by climatic conditions, landscape structure, and the composition of the host community. Survival and development of off-host stages are

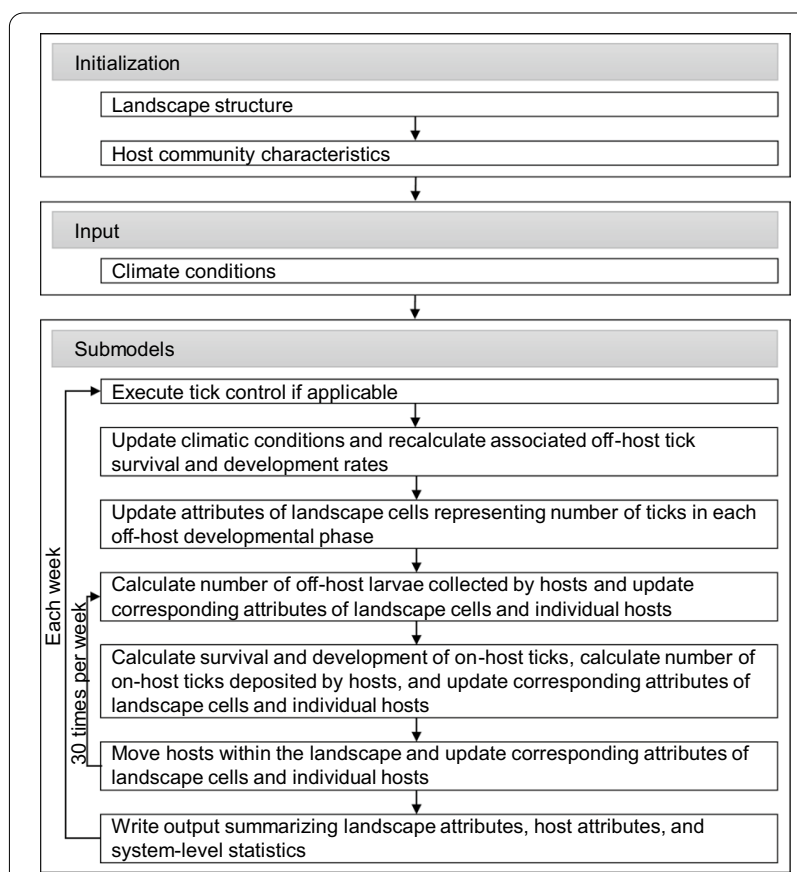

Fig. 2 Overview of the sequence of events and processes involved in the execution of the model simulating the spatial and temporal dynamics of southern cattle fever ticks (SCFTs) (Adapted and modified from Wang et al. [10])

dependent on the temperature and relative humidity in habitat types to which they are exposed as a consequence of host-driven dispersal of gravid females. Completion of the SCFT life cycle depends on larvae encountering an appropriate host, which is influenced by species abundance, composition of the host community, and habitat preferences of potential host species. Spatial and temporal patterns of abundance of off-host SCFT larvae emerge as system-level properties as a result of equations describing rates of off-host tick development and survival, and rules governing the movements of hosts within the landscape (Additional file 1).

\section{Model application}

For the present application, we characterized the modeled landscape on the basis of the dominant vegetation types (sensu McMahan [38]), which consisted of 30\% wood/shrub community dominated by mesquite (wood/ shrub), 30\% mixed-brush community dominated by thorn shrubs (mixed-brush), and 40\% meadow community dominated by grasses, forbs, and grass-like plants (grass) (Fig. 3a). Following Wang et al. [10], we assumed that wood/shrub, mixed-brush, and grass communities represented good, fair, and poor habitats, respectively, with regard to survival rates of host-seeking tick 
larvae. We modified the representation of WTD habitat use preference for good SCFT habitat such that it could be altered from no use to exclusive use (i.e. WTD could spend $0-100 \%$ of their time in good SCFT habitat), with the remaining use preferences split equally between fair and poor habitats. Habitat use preferences of cattle reflected values from Wang et al. [10]: 0.3 for good (wood/shrub), 0.1 for fair (mixed-brush), and 0.6 for poor (grass) SCFT habitat. When present, host densities ( 0.125 cattle/ha, $0.6175 \mathrm{WTD} /$ ha) and activity ranges (300 ha for cattle, 675 ha for WTD) also reflected values from Wang et al. [10].

We simulated a 1-year pasture vacation experiment under different assumptions regarding WTD habitat use preferences. We used a 3-year simulation period (prevacation year, vacation year, and 1st year post-vacation) in which cattle were removed from the system at the beginning (1st week in January) of the vacation year, and were restocked at the beginning of the 1st year post-vacation. The experimental design consisted of 5 Monte Carlo simulations for each of 11 WTD habitat use preferences for good SCFT habitat (0-1 in increments of 0.1, e.g. when preference was 0, WTD did not enter good SCFT habitat; when preference was 0.5 , WTD spent $\approx 50 \%$ of their time in good SCFT habitat; when preference was 1, WTD did not leave good SCFT habitat). As in Wang et al. [10], simulated climatic conditions were generated based on historical temperature, saturation deficit, and precipitation data for Corpus Christi, Texas (Fig. 3b). During each simulation, we monitored numbers of host-seeking larvae in each landscape cell each week. We summarized results in terms of (1) the number of weeks following the end of the pasture vacation needed to reach $100 \%$ of the pre-vacation host-seeking larval density at the landscape scale; (2) the lowest mean host-seeking larval densities at the landscape scale and in each habitat type following the end of pasture vacation; and (3) spatial distributions of host-seeking larvae from immediately pre-vacation through 1 -year post-vacation.

\section{Results}

Mean weekly host-seeking larval densities at the landscape scale varied seasonally in a similar manner regardless of WTD habitat use preferences (Fig. 4a). Larval densities declined sharply within the first 6 weeks of pasture vacation, and continued decreasing to lows of $<100 /$ ha ( $\approx 65-95 /$ ha, depending on WTD preferences) by week 34 . Larval densities then increased slightly during a period of increased precipitation and moderate temperatures during the last quarter of the vacation year, and finally decreased again to below 100/ha. Following the return of cattle (1st week in January of the postvacation year) and onset of warmer temperatures $(\approx 10$ weeks post-vacation), larval densities began increasing

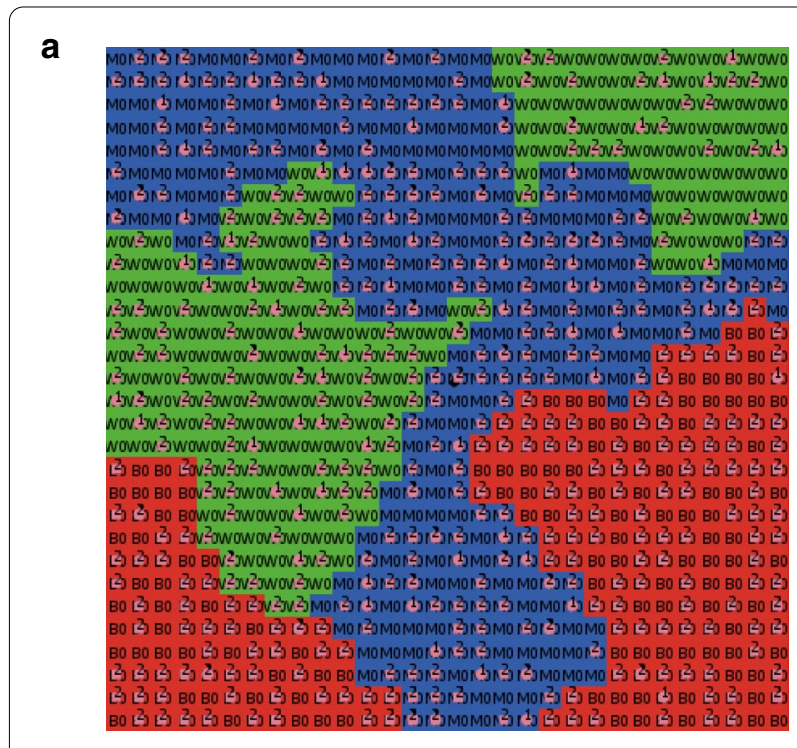

b

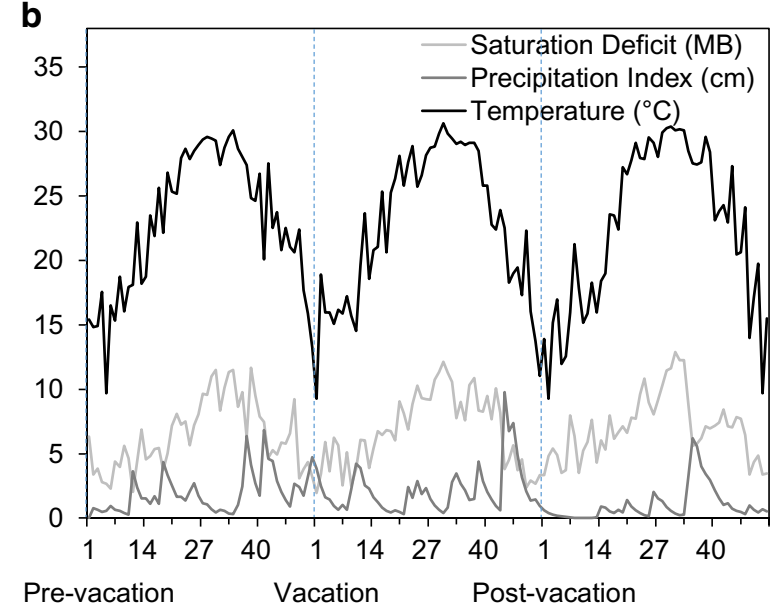

Fig. 3 a Spatial distribution of habitat types across the simulated landscape, consisting of $30 \%$ wood/shrub (good SCFT) habitats (green with W0), 30\% mixed-brush (fair SCFT) habitats (red with BO), and $40 \%$ grass (poor SCFT) habitats (blue with MO). Pink dots with the number 1 represent cattle, pink dots with the number 2 represent white-tailed deer (WTD). b Weather profile during the 3-year simulation period based on historical temperature, saturation deficit, and precipitation data for Corpus Christi, Texas, USA. Vacation "Pasture vacation"

from their post-vacation lows and recovered to $>60 \%$ of pre-vacation densities $(\approx 4800 /$ ha $) \approx 21$ weeks postvacation. In less than a year $(\approx 46$ weeks post-vacation), larval densities reached pre-vacation levels $(\approx 8000 /$ ha $)$, and resumed typical seasonal and year-to-year fluctuations thereafter.

Trends in larval densities in different habitat types paralleled those at the landscape scale during all scenarios (Fig. 4b-d). Not surprisingly, as WTD habitat use preferences for wood/shrub increased (from 0 to 1) across scenarios, larval densities increased in wood/shrub habitats 


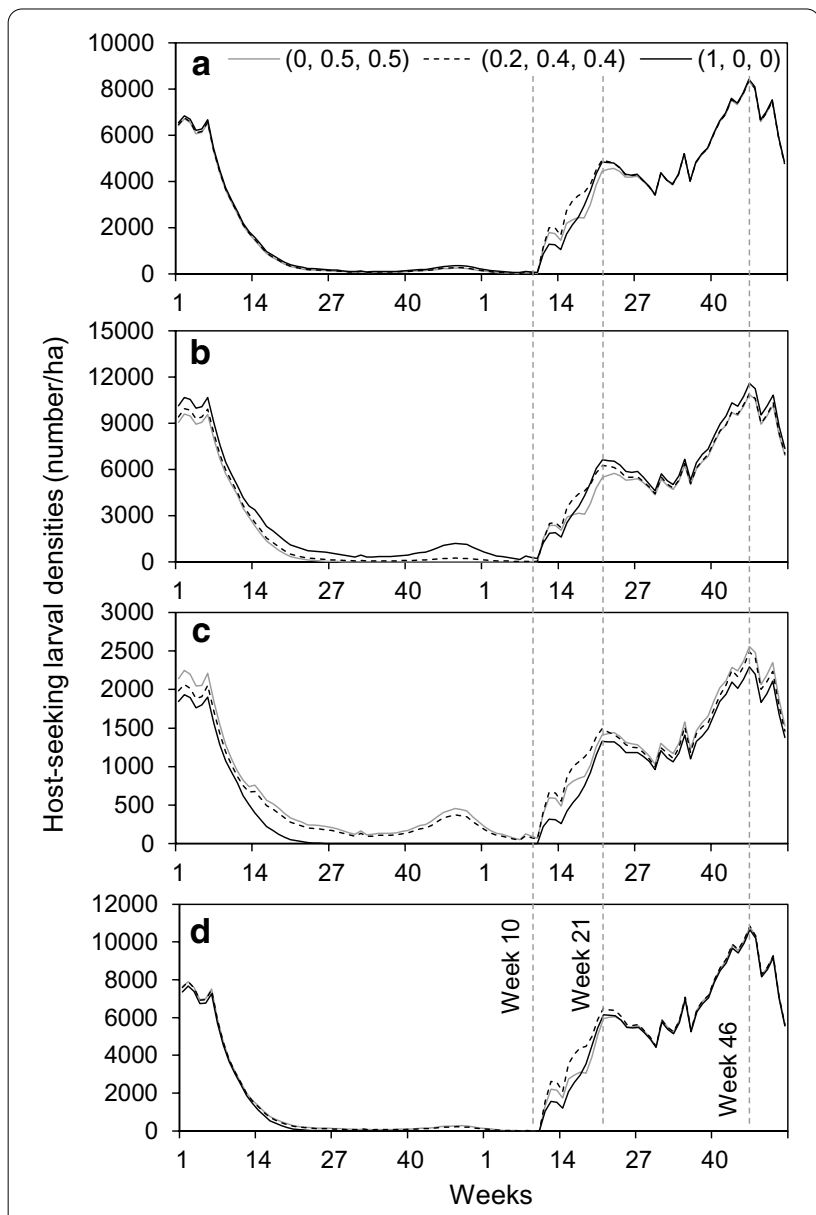

Fig. 4 a-d Temporal response of SCFT host-seeking larval densities under different WTD habitat use preferences during the vacation and post-vacation years (pre-vacation year not shown). Weekly mean numbers of host-seeking larvae per ha are shown at the landscape scale (a) and by habitat type: wood/shrub (b), mixed-brush (c), and grass (d). Results are from simulations in which WTD habitat use preferences for wood/shrub (good SCFT) habitats, mixed-brush (fair SCFT) habitats, and grass (poor SCFT) habitats were $0,0.5,0.5$ (gray solid line), 0.2, 0.4, 0.4 (dashed line), and 1, 0, 0 (black solid line), respectively. Dashed vertical lines representing weeks 10,21, and 46 of the post-vacation year are included for reference

and decreased in mixed-brush and grass habitats. When preference for wood/shrub was 0 (WTD spent $50 \%$ of time in mixed-brush and $50 \%$ in grass), larval densities in wood/shrub decreased to lows of $\approx 50 /$ ha, and to lows of $\approx 50 /$ ha and $\approx 1$ /ha in mixed-brush and grass, respectively. When WTD habitat use preference for wood/ shrub was 1 (WTD used wood/shrub exclusively), larval densities during the vacation year decreased to lows of $\approx 200 /$ ha in wood/shrub, and SCFTs were eliminated from mixed-brush and grass habitats. However, following the return of the cattle and the onset of warmer temperatures, larval density differences among habitats essentially disappeared.
Distribution of larval densities among habitat types at their lowest point, 10 weeks post-vacation, was higher in mixed-brush when WTD habitat use preferences for wood/shrub were $\leq 0.3$ and was higher in wood/shrub when preferences were $\geq 0.4$; larval densities always were lowest in grass (Fig. 5). Thus, relative larval densities (highest to lowest) shifted from wood/shrub, grass, mixed-brush during the pre-vacation period to mixedbrush, wood/shrub, grass or wood/shrub, mixed-brush, grass during the post-vacation period, depending on WTD habitat use preferences.

Spatial distributions of host-seeking larvae immediately pre-vacation and 1-year post-vacation were similar, regardless of WTD habitat use preferences; however, distributions immediately following the vacation period differed depending on preferences (Fig. 6). The rate of spatial expansion post-vacation of relatively densely infested areas was similar regardless of preferences, and by week 21 post-vacation, spatial distributions of hostseeking larvae also were similar.

\section{Discussion}

The simulated effects of WTD habitat use preferences on the efficacy of pasture vacation can be summarized by shifts in the distribution of host-seeking larvae among habitat types during the pasture vacation. These shifts in larval distributions did not have the hypothesized effect on subsequent rates of pasture infestation. Rather, they provided potential SCFT refugia from which recrudescence of infestations could originate. Pre-vacation distributions of host-seeking larvae primarily reflected habitat use preferences of cattle, superimposed on

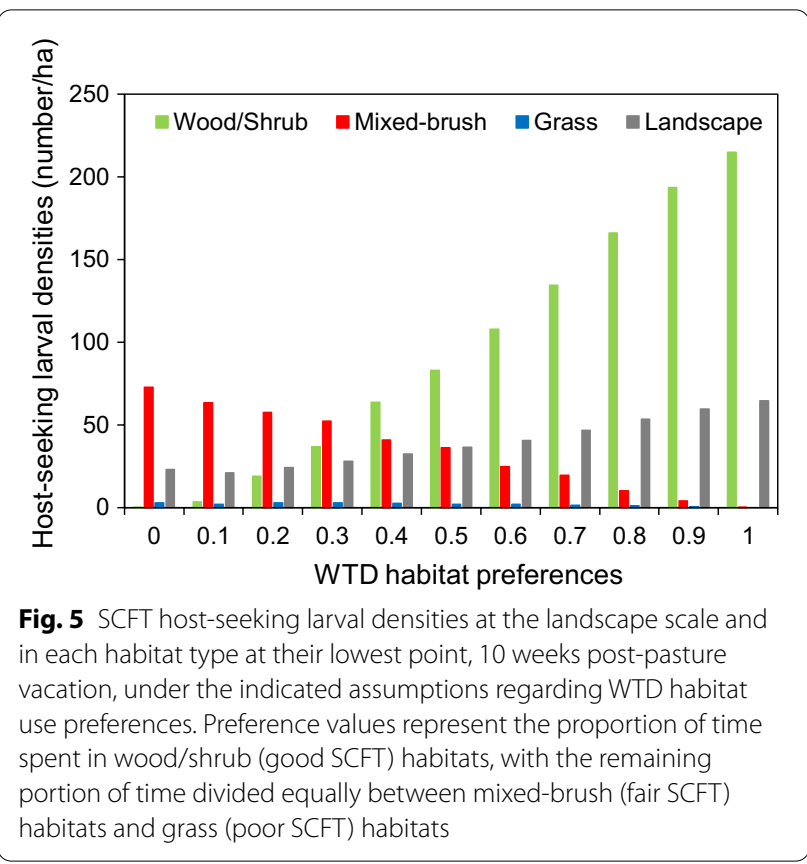




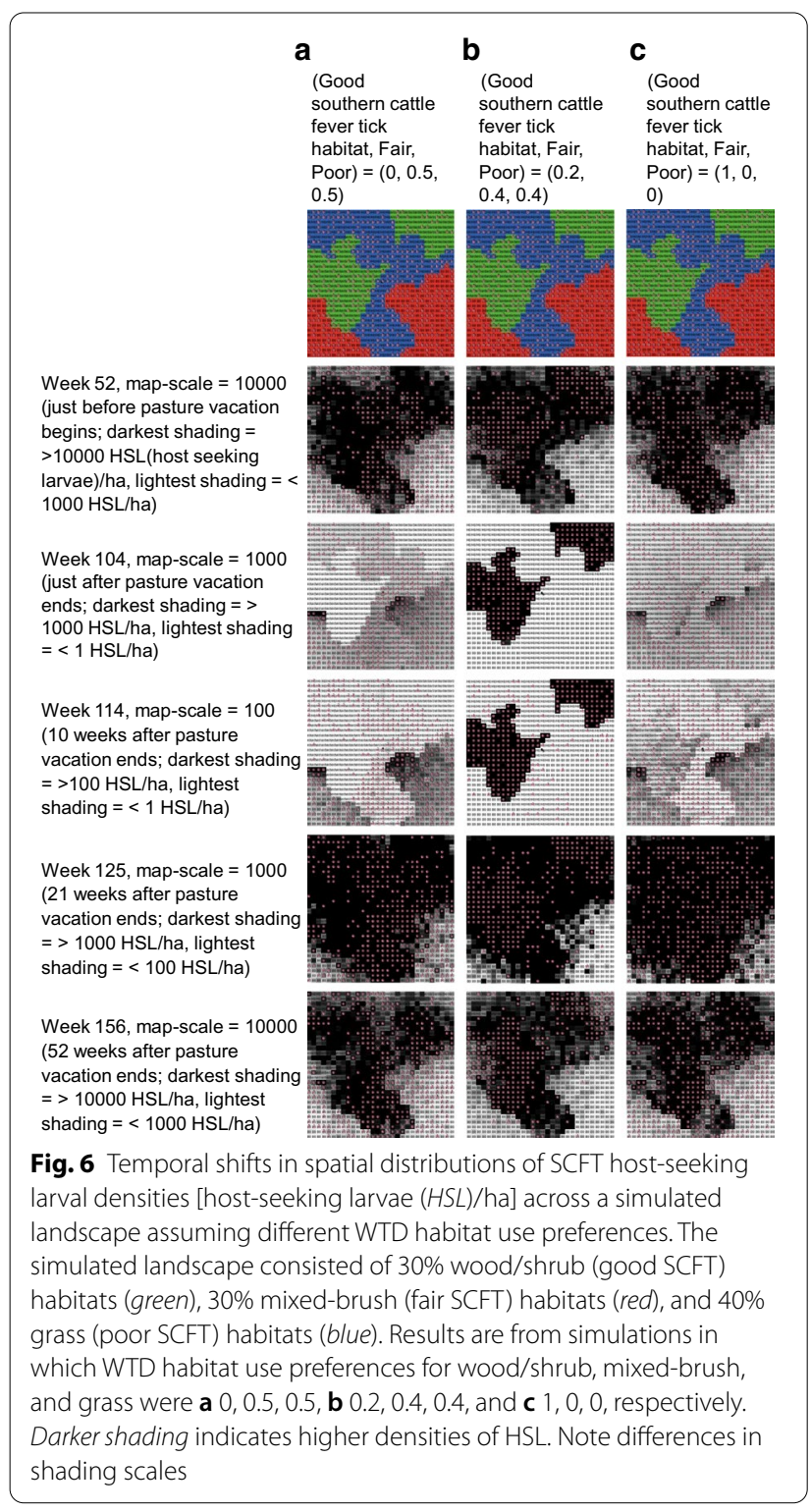

habitat-specific differences in larval survival, thus masking the role of WTD in the maintenance of larvae. Larval densities were highest in wood/shrub, which was used relatively frequently ( $\approx 30 \%$ of the time) by cattle and in which larval survival was highest, followed by grass, which was used most frequently $(\approx 60 \%)$ by cattle but in which larval survival was lowest. Larval densities were lowest in mixed-brush, where survival was intermediate and cattle use was lowest $(\approx 10 \%)$. Post-vacation, before tick population recovery began, relative larval densities primarily reflected habitat use preferences of WTD, again superimposed on habitat-specific differences in larval survival. When WTD preferences were close to those assumed by Wang et al. [10] $(\approx 20 \%$ of time in wood/ shrub, $\approx 40 \%$ in mixed-brush, $\approx 40 \%$ in grass), larval densities were highest in mixed-brush. If time spent in wood/shrub was roughly double that assumed by Wang et al. [10], larval densities were highest in wood/shrub. If time spent in wood/shrub was lower than that assumed by Wang et al. [10], host-seeking larvae were essentially confined within mixed-brush refugia.

The potential for the existence of tick refugia is inherent in the heterogeneous distribution of favorable tick habitats and varied patterns of landscape use by cattle and WTD [39]. Landscape use by cattle and WTD in south Texas rangelands has been the subject of many investigations focused on animal production or conservation goals [29, 39-41]. Species-specific preferences for forage or browse create spatial layers of landscape use, which, in combination with spatially variable physical environmental conditions, form the tick-host-landscape mosaic where CFT populations exist [42, 43], and where CFT eradication efforts operate [3].

By monitoring the WTD-driven shifts in distributions of host-seeking larvae among habitat types during our simulated pasture vacation experiments, we were able to identify potential SCFT refugia from which recrudescence of infestations could originate following reintroduction of cattle. The importance of feedback mechanisms at the habitat-wildlife-livestock interface in the control of infectious diseases is recognized globally [44-47]. Pérez de León et al. [3] have stressed the importance of explicit consideration of habitat use patterns of wildlife hosts in the development of integrated strategies for CFT eradication. Recent studies have focused on movements of WTD as hosts of CFTs [26], while others have highlighted the ecological plasticity of CFTs [48], as factors complicating tick control measures. Within the present context, our model provides an investigative tool that could inform, for example, timely applications of acaricides to specific refugia habitats immediately prior to termination of pasture vacations [49]. Future model applications might simulate management schemes conducted on real landscapes that included different combinations and densities of potential wildlife host species. Of high priority would be simulations assessing the efficacy of acaricide applications to, and culling of, wildlife hosts on landscapes located near the permanent CFT quarantine zone, where nilgai (Boselaphus tragocamelus) have been implicated in potential CFT reinfestations [7]. We hasten to add that our model is not intended to make precise predictions, but, rather, to provide an exploratory tool with which to investigate potential effects of habitat preferences of WTD and other potential wildlife hosts on the efficacy of pasture vacations. 


\section{Conclusions}

Although cattle are the main hosts of CFT, WTD are also confirmed hosts in and around the permanent CFT quarantine zone along the US-Mexico border. Recent CFT infestations outside the quarantine zone pose a serious threat to the US cattle industry. The effects of interactions among host species composition, habitat heterogeneity, and climatic variability on the efficacy of CFT eradication strategies are virtually impossible to investigate in the field. The effects of habitat use preferences of WTD, as well as other potential wildlife hosts, are poorly understood within the context of CFT management. Spatially explicit, individual-based models such as the present one are useful tools for identifying CFT distribution patterns that emerge from a wide variety of tick-host-habitat-climate interactions. Such models allow preliminary a priori evaluation of alternative eradication strategies, including novel strategies involving new technologies, which might require significant investment before a field trial would be possible.

\section{Supplementary Information}

The online version contains supplementary material available at https://doi. org/10.1186/s13071-021-04590-z.

Additional file 1. Summary of model parameters and equations.

\section{Abbreviations}

CFT: Cattle fever tick; CFTEP: Cattle Fever Tick Eradication Program; SCFT: Southern cattle fever tick; WTD: White-tailed deer.

\section{Acknowledgements}

The authors acknowledge the support from Texas A\&M University and Welder Wildlife Foundation faculty and staff. This is Welder Wildlife Foundation publication number no. 722.

\section{Authors' contributions}

MSA and WEG conceived the study. MSA organized the database, analyzed and interpreted the results, assisted with simulation model development, and prepared the manuscript. WEG developed the simulation model and assisted with manuscript preparation and revision. H-HW assisted with model development, manuscript preparation, and revision. All the authors read and approved the final manuscript.

\section{Funding}

No funding was received for this article.

\section{Availability of data and materials}

Not applicable.

Ethics approval and consent to participate

Not applicable.

\section{Consent for publication \\ Not applicable.}

\section{Competing interests}

The authors declare that they have no competing interests.

\section{Author details}

${ }^{1}$ Department of Wildlife and Fisheries Sciences, Texas A\&M University, College Station, TX 77843, USA. ${ }^{2}$ Present Address: Western EcoSystems Technology, Inc. (WEST), Bismarck, ND 58503, USA. ${ }^{3}$ Department of Ecology and Conservation Biology, Texas A\&M University, College Station, TX 77843, USA.

Received: 2 July 2020 Accepted: 11 January 2021

Published online: 08 February 2021

References

1. Gohil S, Herrmann S, Günther S, Cooke BM. Bovine babesiosis in the 21st century: advances in biology and functional genomics. Int J Parasitol. 2013;43(2):125-32. https://doi.org/10.1016/j.ijpara.2012.09.008.

2. Pérez de León AA, Strickman DA, Knowles DP, Fish D, Thacker E, de la Fuente J, et al. One Health approach to identify research needs in bovine and human babesioses: workshop report. Parasites Vectors. 2010;3(1):36. https://doi.org/10.1186/1756-3305-3-36.

3. Pérez de León A, Teel P, Auclair A, Messenger M, Guerrero F, Schuster G, et al. Integrated strategy for sustainable cattle fever tick eradication in USA is required to mitigate the impact of global change. Front Physiol. 2012. https://doi.org/10.3389/fphys.2012.00195.

4. Uilenberg G. Babesia-a historical overview. Vet Parasitol. 2006;138(1):310. https://doi.org/10.1016/j.vetpar.2006.01.035.

5. USDA-APHIS. Cattle Fever Tick Eradication Program: tick control barrier. Maverick, Starr, Webb, and Zapata counties, Texas — draft environmental impact statement. US Department of Agriculture (USDA), Animal and Plant Health Inspection Service (APHIS); 2013.

6. TAHC. News release: fever ticks confirmed on a Webb County premises outside of the permanent quarantine zone. Texas Animal Health Commission (TAHC); 2019.

7. Lohmeyer KH, May MA, Thomas DB, Pérez de León AA. Implication of nilgai antelope (Artiodactyla: Bovidae) in reinfestations of Rhipicephalus (Boophilus) microplus (Acari: Ixodidae) in south Texas: a review and update. J Med Entomol. 2018;55(3):515-22. https://doi.org/10.1093/jme/ tjy004.

8. Senbill H, Hazarika LK, Baruah A, Borah DK, Bhattacharyya B, Rahman S. Life cycle of the southern cattle tick, Rhipicephalus (Boophilus) microplus Canestrini 1888 (Acari: Ixodidae) under laboratory conditions. Syst Appl Acarol. 2018;23(6):1169-79. https://doi.org/10.11158/saa.23.6.12.

9. Teel PD. Application of modelling to the ecology of Boophilus annulatus (Say) (Acari: Ixodidae). J Agric Entomol. 1991;8(4):291-6.

10. Wang H-H, Teel PD, Grant WE, Schuster G, Pérez de León AA. Simulated interactions of white-tailed deer (Odocoileus virginianus), climate variation and habitat heterogeneity on southern cattle tick (Rhipicephalus (Boophilus) microplus) eradication methods in south Texas, USA. Ecol Model. 2016;342:82-96. https://doi.org/10.1016/j.ecolmodel.2016.10.001.

11. Mount GA, Haile DG, Davey RB, Cooksey LM. Computer simulation of Boophilus cattle tick (Acari: Ixodidae) population dynamics. J Med Entomol. 1991;28(2):223-40. https://doi.org/10.1093/jmedent/28.2.223.

12. Davey RB, Cooksey LM, Despins JL. Survival of larvae of Boophilus annulatus, Boophilus microplus, and Boophilus hybrids (Acari: Ixodidae) in different temperature and humidity regimes in the laboratory. Vet Parasitol. 1991;40(3):305-13. https://doi.org/10.1016/0304-4017(91)90110-H.

13. Leal B, Thomas DB, Dearth RK. Population dynamics of off-host Rhipicephalus (Boophilus) microplus (Acari: Ixodidae) larvae in response to habitat and seasonality in south Texas. Vet Sci. 2018;5(2):33.

14. Teel PD, Marin SL, Grant WE. Simulation of host-parasite-landscape interactions: influence of season and habitat on cattle fever tick (Boophilus sp.) population dynamics. Ecol Model. 1996;84(1):19-30. https://doi. org/10.1016/0304-3800(94)00142-1.

15. Teel PD, Marin S, Grant WE, Stuth JW. Simulation of host-parasite-landscape interactions: influence of season and habitat on cattle fever tick (Boophilus sp.) population dynamics in rotational grazing systems. Ecol Model. 1997;97(1):87-97. https://doi.org/10.1016/S0304-3800(96)00076-2.

16. Pound JM, George JE, Kammlah DM, Lohmeyer KH, Davey RB. Evidence for role of white-tailed deer (Artiodactyla: Cervidae) in epizootiology of cattle ticks and southern cattle ticks (Acari: Ixodidae) in reinfestations along the Texas/Mexico border in south Texas: a review and update. J Econ Entomol. 2010;103(2):211-8. https://doi.org/10.1603/ec09359. 
17. Holman PJ, Carroll JE, Pugh R, Davis DS. Molecular detection of Babesia bovis and Babesia bigemina in white-tailed deer (Odocoileus virginianus) from Tom Green County in central Texas. Vet Parasitol. 2011;177(3):298304. https://doi.org/10.1016/j.vetpar.2010.11.052

18. Busch JD, Stone NE, Nottingham R, Araya-Anchetta A, Lewis J, Hochhalter $C$, et al. Widespread movement of invasive cattle fever ticks (Rhipicephalus microplus) in southern Texas leads to shared local infestations on cattle and deer. Parasites Vectors. 2014;7(1):188. https:// doi.org/10.1186/1756-3305-7-188.

19. Clements GM, Hygnstrom SE, Gilsdorf JM, Baasch DM, Clements MJ, Vercauteren KC. Movements of white-tailed deer in riparian habitat: implications for infectious diseases. J Wildl Manage. 2011;75(6):143642. https://doi.org/10.1002/jwmg.183.

20. Wang H-H, Grant WE, Teel PD, Hamer SA. Simulation of climate-tickhost-landscape interactions: effects of shifts in the seasonality of host population fluctuations on tick densities. J Vector Ecol. 2015;40(2):24755. https://doi.org/10.1111/jvec.12161.

21. Wang H-H, Grant WE, Teel PD, Lohmeyer KH, Pérez de León A. Enhanced biosurveillance of high-consequence invasive pests: southern cattle fever ticks, Rhipicephalus (Boophilus) microplus, on livestock and wildlife. Parasites Vectors. 2020;13(1):487. https://doi.org/10.1186/ s13071-020-04366-X.

22. Wang H-H, Teel PD, Grant WE, Soltero F, Urdaz J, Ramírez AEP, et al. Simulation tools for assessment of tick suppression treatments of Rhipicephalus (Boophilus) microplus on non-lactating dairy cattle in Puerto Rico. Parasites Vectors. 2019;12(1):185. https://doi.org/10.1186/s1307 1-019-3443-6.

23. Graham $\mathrm{OH}$, Hourrigan JL. Review article: eradication programs for the arthropod parasites of livestock. J Med Entomol. 1977;13(6):629-58. https ://doi.org/10.1093/jmedent/13.6.629.

24. TAHC. Cattle fever tick. Austin: Texas Animal Health Commission (TAHC); 2017.

25. Abbas RZ, Zaman MA, Colwell DD, Gilleard J, labal Z. Acaricide resistance in cattle ticks and approaches to its management: the state of play. Vet Parasitol. 2014;203(1):6-20. https://doi.org/10.1016/j.vetpar.2014.03.006.

26. Currie CR. Influence of white-tailed deer on cattle fever tick eradication efforts in southern Texas. Kingsville: Texas A\&M University-Kingsville; 2013.

27. Miller RJ, Davey RB, George JE. First report of organophosphate-resistant Boophilus microplus (Acari: Ixodidae) within the United States. J Med Entomol. 2005:42(5):912-7. https://doi.org/10.1093/jmedent/42.5.912

28. Sanders CL. Habitat preferences of the white-tailed deer and several exotic ungulates in south Texas. Ecology. 1963;44(4):803-6. https://doi. org/10.2307/1933036. http://www.jstor.org/stable/1933036.

29. Inglis JM, Hood RE, Brown BA, DeYoung CA. Home range of white-tailed deer in Texas coastal prairie brushland. J Mammal. 1979;60(2):377-89. https://doi.org/10.2307/1379810. http://www.jstor.org/stable/1379810.

30. Beier P, McCullough DR. Factors influencing white-tailed deer activity patterns and habitat use. Wildl Monogr. 1990:3-51.

31. Brunjes KJ, Ballard WB, Humphrey MH, Harwell F, Mclntyre NE, Krausman PR, et al. Habitat use by sympatric mule and white-tailed deer in Texas. J Wildl Manage. 2006;70(5):1351-9.

32. Pollock MT, Whittaker DG, Demarais S, Zaiglin RE. Vegetation characteristics influencing site selection by male white-tailed deer in Texas. J Range Manage. 1994;47(3):235-9.

33. Avey JT, Ballard WB, Wallace MC, Humphrey MH, Krausman PR, Harwell F, et al. Habitat relationships between sympatric mule deer and whitetailed deer in Texas. Southwest Nat. 2003;48(4):644-53.

34. DeYoung CA, Fulbright TE, Hewitt DG, Wester DB, Draeger DA, DeYoung C. Linking white-tailed deer density, nutrition, and vegetation in a stochastic environment. Wildl Monogr. 2019;202:1-63.

35. Grimm V, Berger U, DeAngelis DL, Polhill JG, Giske J, Railsback SF. The ODD protocol: a review and first update. Ecol Model. 2010;221(23):2760-8. https://doi.org/10.1016/j.ecolmodel.2010.08.019.

36. Grimm V, Berger U, Bastiansen F, Eliassen S, Ginot V, Giske J, et al. A standard protocol for describing individual-based and agent-based models. Ecol Model. 2006;198(1-2):115-26. https://doi.org/10.1016/j.ecolm odel.2006.04.023

37. Grimm V, Railsback SF, Vincenot CE, Berger U, Gallagher C, DeAngelis DL, et al. The ODD protocol for describing agent-based and other simulation models: a second update to improve clarity, replication, and structural realism. J Artif Soc Soc Simul. 2020;23(2):7.
38. McMahan C, Frye R, Brown K. The vegetation types of Texas including cropland: an illustrated synopsis to accompany the map. Issue 120 of the TPWD Bulletin. Austin: Texas Parks and Wildlife Department (TPWD), Wildlife Division; 1984.

39. Cohen WE, Drawe DL, Bryant FC, Bradley LC. Observations on white-tailed deer and habitat response to livestock grazing in south Texas. J Range Manage. 1989;42(5):361-5.

40. McMahan CA, Inglis JM. Use of Rio Grande Plain brush types by whitetailed deer. J Range Manage. 1974;27(5):369-74.

41. Cooper SM, Perotto-Baldivieso HL, Owens MK, Meek MG, Figueroa-Pagán M. Distribution and interaction of white-tailed deer and cattle in a semiarid grazing system. Agric Ecosyst Environ. 2008;127(1):85-92. https://doi. org/10.1016/j.agee.2008.03.004.

42. Estrada-Peña A, de la Fuente J, Latapia T, Ortega C. The impact of climate trends on a tick affecting public health: a retrospective modeling approach for Hyalomma marginatum (Ixodidae). PLoS ONE. 2015;10(5):e0125760. https://doi.org/10.1371/journal.pone.0125760.

43. Estrada-Peña A, Alexander N, Wint GRW. Perspectives on modelling the distribution of ticks for large areas: so far so good? Parasites Vectors. 2016:9(1):179. https://doi.org/10.1186/s13071-016-1474-9.

44. Miller RS, Farnsworth ML, Malmberg JL. Diseases at the livestock-wildlife interface: status, challenges, and opportunities in the United States. Prev Vet Med. 2013;110(2):119-32. https://doi.org/10.1016/j.preve tmed.2012.11.021.

45. Wiethoelter AK, Beltrán-Alcrudo D, Kock R, Mor SM. Global trends in infectious diseases at the wildlife-livestock interface. Proc Natl Acad Sci. 2015;112(31):9662-7. https://doi.org/10.1073/pnas.1422741112. https:// www.pnas.org/content/pnas/112/31/9662.full.pdf.

46. Wang $\mathrm{H}-\mathrm{H}$, Grant WE, Teel PD, Hamer SA. Tick-borne infectious agents in nature: simulated effects of changes in host density on spatial-temporal prevalence of infected ticks. Ecol Model. 2016;323:77-86. https://doi. org/10.1016/j.ecolmodel.2015.11.021.

47. Wang H-H, Grant WE, Teel PD. Simulation of climate-host-parasite-landscape interactions: a spatially explicit model for ticks (Acari: Ixodidae). Ecol Model. 2012;243:42-62. https://doi.org/10.1016/j.ecolm odel.2012.06.007. http://lib-ezproxy.tamu.edu:2048/login?url=http:// search.ebscohost.com/login.aspx?direct=true \&db=edselp\&AN=S0304 380012002797\&site=eds-live

48. Estrada-Peña A, Salman M. Current limitations in the control and spread of ticks that affect livestock: a review. Agriculture. 2013;3(2):221. http:// www.mdpi.com/2077-0472/3/2/221.

49. Wang $\mathrm{H}-\mathrm{H}$, Corson MS, Grant WE, Teel PD. Quantitative models of Rhipicephalus (Boophilus) ticks: historical review and synthesis. Ecosphere 2017;8(9):e01942. https://doi.org/10.1002/ecs2.1942.

\section{Publisher's Note}

Springer Nature remains neutral with regard to jurisdictional claims in published maps and institutional affiliations.

$$
\begin{aligned}
& \text { Ready to submit your research? Choose BMC and benefit from: } \\
& \text { - fast, convenient online submission } \\
& \text { - thorough peer review by experienced researchers in your field } \\
& \text { - rapid publication on acceptance } \\
& \text { - support for research data, including large and complex data types } \\
& \text { - gold Open Access which fosters wider collaboration and increased citations } \\
& \text { - maximum visibility for your research: over } 100 \mathrm{M} \text { website views per year }
\end{aligned}
$$

\section{At $\mathrm{BMC}$, research is always in progress.}

Learn more biomedcentral.com/submissions 